\title{
Pressure Wave Measurements Resulting from Thermal Cook-Off of the HMX Based High Explosive LX-04
}

F. Garcia, K.S. Vandersall, J.W. Forbes, C.M. Tarver, D. Greenwood

This article was submitted to American Physical Society Topical Conference on Shock Compression of Condensed Matter Portland, OR July 20-25, 2003

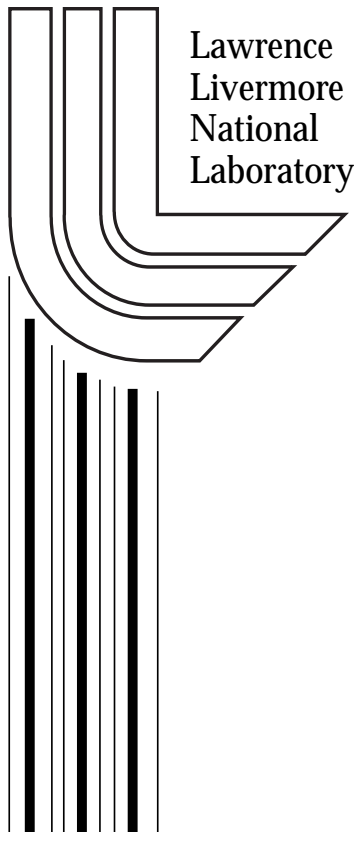

\section{July 11, 2003}




\section{DISCLAIMER}

This document was prepared as an account of work sponsored by an agency of the United States Government. Neither the United States Government nor the University of California nor any of their employees, makes any warranty, express or implied, or assumes any legal liability or responsibility for the accuracy, completeness, or usefulness of any information, apparatus, product, or process disclosed, or represents that its use would not infringe privately owned rights. Reference herein to any specific commercial product, process, or service by trade name, trademark, manufacturer, or otherwise, does not necessarily constitute or imply its endorsement, recommendation, or favoring by the United States Government or the University of California. The views and opinions of authors expressed herein do not necessarily state or reflect those of the United States Government or the University of California, and shall not be used for advertising or product endorsement purposes.

This is a preprint of a paper intended for publication in a journal or proceedings. Since changes may be made before publication, this preprint is made available with the understanding that it will not be cited or reproduced without the permission of the author.

This report has been reproduced directly from the best available copy.

Available electronically at http://www.doc.gov/bridge

Available for a processing fee to U.S. Department of Energy

And its contractors in paper from

U.S. Department of Energy

Office of Scientific and Technical Information

P.O. Box 62

Oak Ridge, TN 37831-0062

Telephone: (865) 576-8401

Facsimile: (865) 576-5728

E-mail: reports@adonis.osti.gov

Available for the sale to the public from

U.S. Department of Commerce

National Technical Information Service

5285 Port Royal Road

Springfield, VA 22161

Telephone: (800) 553-6847

Facsimile: (703) 605-6900

E-mail: orders@ntis.fedworld.gov

Online ordering: http://www.ntis.gov/ordering.htm

OR

Lawrence Livermore National Laboratory

Technical Information Department's Digital Library

http://www.llnl.gov/tid/Library.html 


\title{
PRESSURE WAVE MEASUREMENTS RESULTING FROM THERMAL COOK-OFF OF THE HMX BASED HIGH EXPLOSIVE LX-04
}

\author{
Frank Garcia, Kevin S. Vandersall, Jerry W. Forbes, \\ Craig M. Tarver, and Daniel Greenwood
}

Lawrence Livermore National Laboratory

Livermore, CA 94550

\begin{abstract}
Experiments that investigate thermal and nearby explosion scenarios are needed to provide essential data to models for accurate predictions. A porous LX-04 (85/15 wt\% HMX/Viton) sample was heated in a heavily confined donor charge until it thermally exploded. The reaction accelerated a steel cover plate across a $10 \mathrm{~cm}$ gap into a preheated gauged acceptor cylinder (near its theoretical maximum density) of LX-04. The carbon resistor gauges in the acceptor measured the resulting multi-dimensional ramp wave as it propagated through the pre-heated LX-04. Detonation of the LX-04 acceptor does not occur. Results are compared to similar experiments with acceptors at room temperature.
\end{abstract}

\section{INTRODUCTION}

Because questions exist on the level of violence as a function of confinement and thermal heating rates in thermal explosion events, a better understanding is needed for safe handling, transportation, and storage of explosive devices. Experimental measurements of the violence of thermal explosion events of known sizes, confinements, and thermal histories are essential for developing and calibrating reactive flow computer models for calculating events that are impossible to measure experimentally. In addition, the measured accelerations of metal cases from thermal explosions are also needed to assess whether the resulting flying fragments can shock initiate violent reactions or detonations in neighboring explosive items.
The experiments performed here are referred to as Thermal EXplosion Tests (TEXT). Compared to experiments with slow hating rates of $\sim 1^{\circ} \mathrm{C} /$ hour [1], the relatively quick heating rate $\left(\sim 5.7^{\circ} \mathrm{C} / \mathrm{min}\right.$ until $170^{\circ} \mathrm{C}$, then $1^{\circ} \mathrm{C} / \mathrm{min}$ until explosion) used here allows the combined results to bound the problem. Successful modeling of these two bounds will aid in the understanding of the mechanisms involved. In this paper, pressure gauge measurements are used to quantitatively determine the level of violence in a cook-off experiment and are used to measure low-pressure ramp waves with pulse widths of several microseconds. Carbon resistor gauges $[2,3,7,8]$ have been successfully used in two-dimensional shock wave experiments where time resolution and accuracy were sacrificed for gauge survivability [2-6]. 


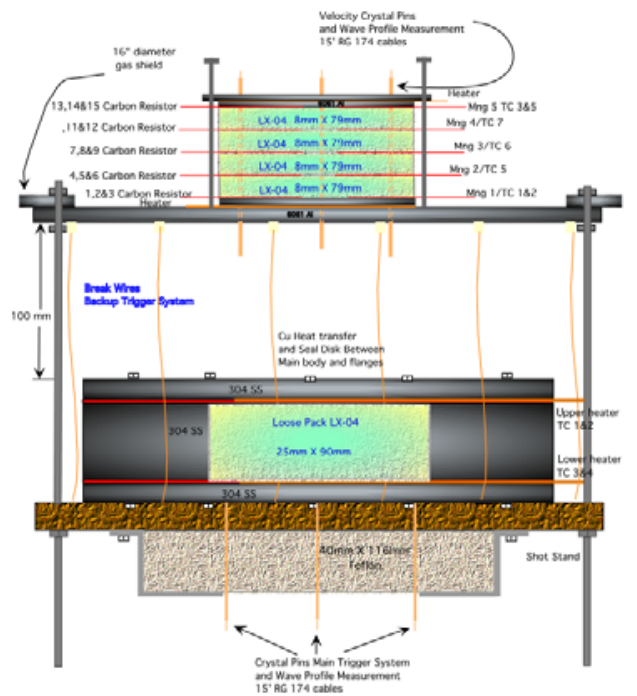

FIGURE 1. Diagram of the TEXT X experiment assembly.

\section{EXPERIMENTAL PROCEDURE}

Three thermal explosion experiments were performed using LX-04 donor charges confined in 304 stainless steel cased donor assemblies. Experiment TEXT VIII used a $1.86 \mathrm{~g} / \mathrm{cc}(98.5 \%$ TMD) LX-04 donor charge with a $1.86 \mathrm{~g} / \mathrm{cc}$ (98.5\% TMD) LX-04 acceptor assembly in intimate contact with the donor. A follow up experiment, TEXT IX, was performed using a porous LX-04 donor charge at $1.05 \mathrm{~g} / \mathrm{cc}(55.6 \%$ TMD) and a Teflon acceptor in intimate contact with the donor. TEXT $\mathrm{X}$ is the third experiment with LX-04 and utilized a porous LX-04 donor (55.6\% TMD) and a heated $1.86 \mathrm{~g} / \mathrm{cc}(98.5 \%$ TMD) LX-04 acceptor assembly at a $10 \mathrm{~cm}$ standoff.

Experiments TEXT VIII and TEXT IX were detailed in a prior publication [6] and will not be fully described here, but will be referred to in the following sections for comparison and discussion. The experiment TEXT $\mathrm{X}$ is shown in Figure 1 with the $79 \mathrm{~mm}$ diameter LX-04 acceptor placed at a $100 \mathrm{~mm}$ standoff from the top steel plate of the donor. Manganin and carbon resistor gauges were placed at the interfaces of the acceptor discs at $0,8,16,24$, and $32 \mathrm{~mm}$ from the front face of the acceptor HE. The acceptor was sitting on a $9.3 \mathrm{~mm}$ thick 304 stainless steel plate placed $100 \mathrm{~mm}$ from donor's steel top plate. Extensive details about the donor assembly, donor heating system, carbon resistor pressure gauges, manganin pressure gauges, thermocouples, PZT pins, pin placement under donor, and acceptor pin placement (15 $\mathrm{mm}$ and $25 \mathrm{~mm}$ standoff) are the same as previous experiments [4,6].

Heating of the donor occurred at a rate of $5.7^{\circ} \mathrm{C}$ a minute until the thermocouples at the heater package recorded $170^{\circ} \mathrm{C}$ and soaked for about 30 minutes. Then the heating rate in the heater package was set at $1{ }^{\circ} \mathrm{C} / \mathrm{min}$ until the explosive thermally reacted. Unique to the experiment described in detail here, TEXT X, is the heating of the acceptor unit. The acceptor was heated in the range of $90-100^{\circ} \mathrm{C}$ at the time of donor cook-off. Because of the large thermal mass at the base of the acceptor assembly, the heating rate was rather erratic and will be discussed further in the results section. The assembled experiments were placed inside a large steel expendable cylinder before firing to protect the firing chamber walls.

\section{RESULTS/DISCUSSION}

The donor assembly in TEXT X cooked off as expected at approximately $230^{\circ} \mathrm{C}$. The acceptor was in the temperature range of 90 $100^{\circ} \mathrm{C}$ when this occurred and the donor cover plate was thrown into the acceptor. The velocity of this plate was measured as approximately $350 \mathrm{~m} / \mathrm{s}$ as indicated by an average of the standoff pins protruding at $15 \mathrm{~mm}$ and $25 \mathrm{~mm}$ from stainless steel acceptor base. The pin arrival times varied indicating that the plate was probably curved like a door knob during impact and that it was not a planar impact.

As mentioned earlier, non-uniform heating of the acceptor was seen due to a large amount of metal surrounding the assembly acting to 
conduct heat away as can be seen in Fig. 2. An overshoot is seen in the top of the acceptor (less metal thermal mass surrounding) as the controller was manually adjusted to slow it down to follow the base heating more closely.

The carbon resistor pressure gauge records are displayed in Fig. 3 and showed a ramp wave with a peak of approximately $0.7 \mathrm{GPa}$ that decayed to about $0.2 \mathrm{GPa}$ in the $32 \mathrm{~mm}$ thick LX-04 sample. The ramp wave in the acceptors did not build into a detonation. Note that these pressures are based on a calibration of the gauges at $25^{\circ} \mathrm{C}$. The gauges have not yet been calibrated at the elevated temperature, but ambient temperature heating shows that the initial resistance changes less than $2 \%$ when heated to $100^{\circ} \mathrm{C}[8]$, so the change in calibration is expected to be relatively small.

These results are consistent with the previous LX-04 cook-off experiments. TEXT VIII had a full density donor during cook-off and did not have significant violence to even blow off the donor charge cover plates. This was the reason for going to the porous donor in TEXT IX, which sent a ramp wave into the Teflon acceptor in contact with donor top plate with peak pressures of $0.8 \mathrm{GPa}$ and a decaying ramp wave. The porosity plays an essential part in allowing the LX-04 to accumulate appreciable violence during thermal explosion.

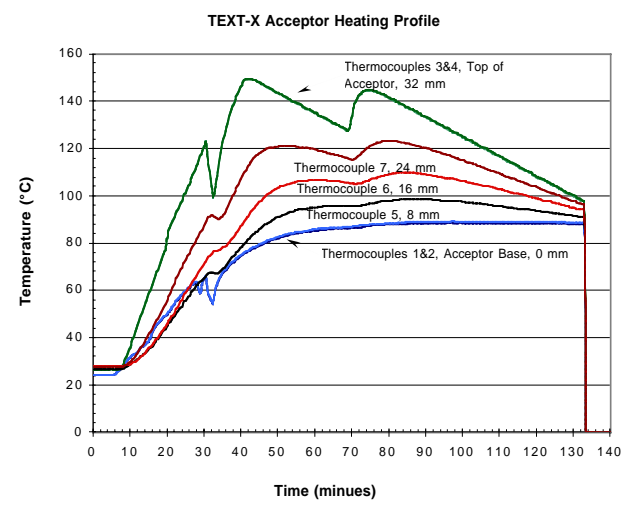

FIGURE 2. Heating profile of the acceptor assembly.

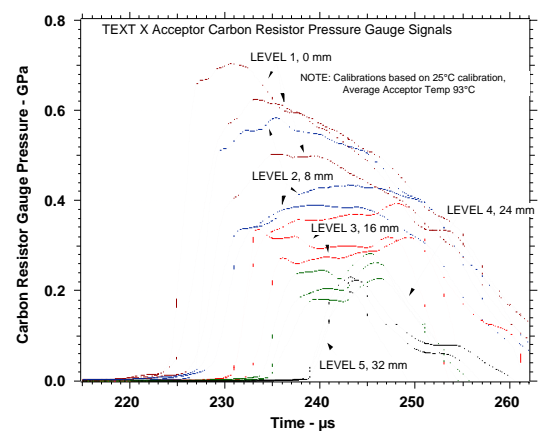

FIGURE 3. Pressure profiles of the carbon resistor gauges in the acceptor assembly.

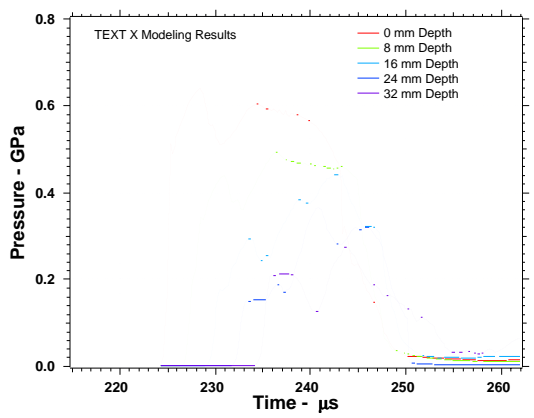

FIGURE 4. Modeling calculations of the pressure profiles at carbon resistor gauges locations in the acceptor assembly.

The DYNABURN option of the Ignition and Growth model was used as in Forbes et al. [6] to calculate experiments TEXT IX and X. The only changes were to lower the initial LX-04 density to $1.05 \mathrm{~g} / \mathrm{cm}^{3}$, the shear modulus to 0.9 $\mathrm{GPa}$, the yield strength to $0.03 \mathrm{GPa}$, and the initial energy to $0.058 \mathrm{Mbar}-\mathrm{cm}^{3} / \mathrm{cm}^{3}-\mathrm{g}$. The growth of reaction coefficient $\mathrm{G}_{1}$ was adjusted to yield a low density LX-04 deflagration velocity that accelerated the steel plate in TEXT X to a final velocity of $350 \mathrm{~m} / \mathrm{s}$. This deflagration velocity also yielded good agreement with the pressures measured in the teflon acceptor in TEXT IX. Figure 4 shows the calculated pressure histories at the various gauge depths in heated LX-04 used in TEXT X, which can be compared to the experimental measurements shown in Fig. 3. The calculated peak pressures agree well with the gauge records, but the gauges show longer rise times and later arrival times. To improve the model 
results, the simple low-pressure elastic-plastic description of LX-04 needs to be more complex. The full density LX-04 reactive flow model suggests that the heated LX-04 acceptor did not react at all in TEXT $X$.

\section{SUMMARY AND FUTURE WORK}

A porous LX-04 donor assembly was cooked off and the assembly plate was accelerated into a nearby heated $\left(100^{\circ} \mathrm{C}\right)$ acceptor at a $10 \mathrm{~cm}$ standoff. The carbon resistor pressure gauge results (without temperature corrections) show ramp waves with peak pressures of $0.7 \mathrm{GPa}$ and rise times of $\sim 2 \mu \mathrm{s}$. The ramp pressure wave decays very rapidly (i.e. does not build to detonation) as it moves through the acceptor charge and the rise times become more dispersed. The DYNA2D modeling of this experiment yielded results that are in good agreement with the experiment.

Future work includes TEXT XI as seen in Fig. 5 and TEXT XII experiments that are built and awaiting firing. These experiments use less confinement in the donor assembly with different thickness cover plates. The donor densities are near $1.0 \mathrm{~g} / \mathrm{cc}$.

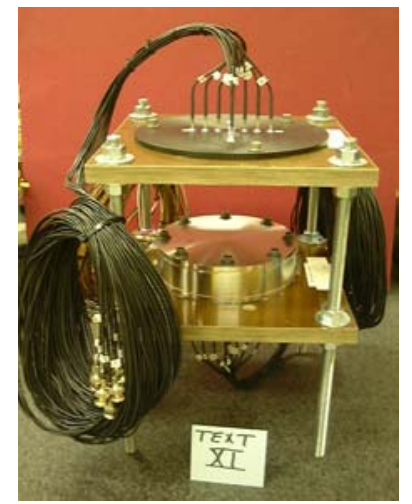

FIGURE 5. Schematic diagram of the upcoming TEXT XI experiment with less confinement.

\section{ACKNOWLEDGEMENTS}

Jerry Dow at LLNL is generously thanked for funding this work. Assistance by Ernie
Urquidez, Rich Villafana, and Gary Steinhour is gratefully acknowledged. Douglas Tasker (LANL) and William Wilson (Eglin AFB) are acknowledged for sharing their information on the use of carbon resistor gauge. The constant current power supply for the carbon resistor gauge was designed by Douglas Tasker. This work was performed under the auspices of the U. S. Department of Energy by the University of California, Lawrence Livermore National Laboratory under Contract No. W-7405-Eng-48.

\section{REFERENCES}

1. Wardell, J. F. and Maienschein, J. L., Proceedings of the 12th International Detonation Symposium, San Diego, CA, August, 2002, in press.

2. Ginsberg, M. J., and Asay, B. W., Rev. Sci. Instrum. 62 (9): 2218-2227 (1991).

3. Wilson, W. M., Holloway, D. C., and Bjarnholt, G., Techniques and Theory of Stress Wave Measurements for Shock Wave Applications (American Society of Mechanical Engineers, New York, 1987), pp. 97-108.

4. Garcia, F., Forbes, J. W., Tarver, C. M., Urtiew, P. A., Greenwood, D. W., and Vandersall, K. S., Shock Compression of Condensed Matter-2001, Furnish, M. D., Thadhani, N. N., and Horie, Y, eds. CP-620, AIP Press, New York, 2002, p. 882.

5. Niles, A. M., Garcia, F., Greenwood, D. W., Forbes, J. W., Tarver, C. M., Chidester, S. K., W., Garza, R, and Swizter, L. L., Shock Compression of Condensed Matter-2001, Furnish, M. D., Thadhani, N. N., and Horie, Y, eds. CP-620, AIP Press, New York, 2002, p. 886.

6. Jerry W. Forbes, Frank Garcia, Craig M. Tarver, Paul A. Urtiew, Daniel W. Greenwood, and Kevin S. Vandersall, Proceedings of the 12th International Detonation Symposium, San Diego, CA, August, 2002, in press.

7. Austing, J. L., Tulis, A. J., Hrdina, D. J., and Baker, D. E., Propellants, Explosives, Pyrotechnics 16, 205 (1991).

8. Cunningham, B., Vandersall, K. S., Niles, A. M., Greenwood, D. W., Garcia, F., Forbes, J. W., and Wilson, W. H., Shock Compression of Condensed Matter-2001, Furnish, M. D., Thadhani, N. N., and Horie, Y, eds. CP-620, AIP Press, New York, 2002, p. 1137. 